\title{
XÂY DỰNG MÔ HÌNH PHÂN TÍCH CHI PHÍ - HIỆU QUẢ ISAVUCONAZOLE TRONG ĐIỀU TRỊ NHIỄM NẤM ASPERGILLUS XÂM LẤN TẠI VIỆT NAM
}

\begin{abstract}
TÓM TẮT.
Nhiễm nấm Aspergillus xâm lấn (Invasive Aspergillosis - IA) là một thể bênh năng trong các thể nhiễm nấm Aspergillus, rất thường gặp ở người bệnh suy giảm miễn dich. Thuốc isavuconazole (ISA) ra đời nhằm thay thế các liệu pháp khác trong điều trị IA với hiệu quả lâm sàng vượt trội đã được chứng minh trong các thử nghiệm lâm sàng. Với phương pháp mô hình hóa kết hợp tổng quan tài liệu và tham vấn ý kiến các chuyên gia lâm sàng, nghiên cứu đã xây dựng được mô hình phân tích CP-HQ trong điều trị IA tại Việt Nam bằng phần mềm Microsoft Excel với cấu trúc mô hình bao gôm 2 phương án lựa chọn điêu trị với các thông số đâuu vào (xác suất, chi phí, hiệu quả) từ đó ước lượng được các thông số đầu ra (chỉ số gia tăng $\mathrm{CP}-\mathrm{HQ}$ và độ nhạy của mô hình). Mô hình xây dựng cho phép phân tích $\mathrm{CP}-\mathrm{HQ}$ của 2 phác đồ và có thể đưa ra kết luân về hiêu quả kinh tế của liệu pháp điều trị hiệu quả tối ưu với chi phí tối thiểu trong điều trị IA.
\end{abstract}

Từ khóa: Phân tích chi phí - hiệu quả, isavuconazole, nhiễm nấm Aspergillosis xâm lấn, mố hình.

\section{SUMMARY \\ CONSTRUCT THE MODEL OF COST - EFFECTIVENESS ANALYSIS OF ISAVUCONAZOLE IN INVASIVE} \section{ASPERGILLOSIS TREATMENT IN VIETNAM}

Invasive Aspergillosis (IA) is a severe form of Aspergillus fungal infection, which common in immunocompromised patients. Isavuconazole (ISA) has been shown to replace other therapies in the treatment of IA with superior clinical efficacy demonstrated in clinical trials. With the modeling method combined with document review and consultation with clinical experts, the CEA model in the treatment of IA in Vietnam has been built using Microsoft Excel software with the following configuration: the model structure includes 2 treatment options with input parameters (probability, cost, effectiveness) from which to estimate output parameters (increase cost-effectiveness ratio and probabilistic sensitivity of model). The model allows to conduct CEA of the 2 regimens and can draw conclusions about the economic efficiency of the optimal effective therapy with minimal cost in the treatment of IA.

* Đai hoc Y Dước TP. Hồ Chí Minh

Chịu trách nhiệm chính: Nguyễn Thị Thu Thủy

Email: nguyenthuthuy@ump.edu.vn

Ngày nhận bài: 24.8.2021

Ngày phản biên khoa học: 18.10.2021

Ngày duyệt bài: 26.10 .2021
Trần Thị Thiên Thy*, Lê Diễm Quỳnh*, Hoàng Kim Trúc*, Nguyễn Thị Thu Thủy*

Keywords: Cost-effectiveness analysis, isavuconazole, Invasive Aspergillosis, model

\section{I. ĐẶT VẤN ĐỀ}

Trong đánh giá kinh tế y tế, mô hình hóa là một phương pháp phổ biến nhất vì những ưu việt và tính cập nhật cũng như linh động của mô hình. Isavuconazole (ISA) được Cục Quản lý Thực phẩm và Dược phẩm Hoa Kỳ (Food and Drug Administration - FDA) công nhận vào tháng 03/2015 như một liệu pháp thay thế voriconazole (VORI) trong điều trị nhiễm nấm Aspergillus xâm lấn (Invasive Aspergillosis - IA) ${ }^{(5)}$. Mặc dù nhiều nghiên cứu phân tích chi phí - hiệu quả (CP-HQ) của ISA trong điều trị IA đã được tiến hành ở các nước thế giới như Mỹ ${ }^{(4)}$, Thụy Điển ${ }^{(2)}, A h^{(3)}$ và Tây Ban Nha ${ }^{(1)}$ bằng phương pháp mô hình hóa. Tuy nhiên tại Việt Nam hiện nay vẫn chưa có nghiên cứu tương tự nào được thực hiện và hơn thế nữa công cụ quan trọng để phân tích $\mathrm{CP}-\mathrm{HQ}$ là xây dựng mố hình hóa phù hợp với bối cảnh điều trị thực tế tại Việt Nam. Chính vì thế, nghiên cứu được tiến hành nhằm mục đích xây dựng mô hình hóa để mô phỏng các phương án điều trị có thể thực hiện tạo công cụ phân tích $\mathrm{CP}-\mathrm{HQ}$ của ISA trong điều trị IA.

\section{II. ĐỐI TƯỢNG VÀ PHƯƠNG PHÁP NGHIÊN CỨU}

2.1. Đối tượng nghiên cứu: Mô hình phân tích chi phí hiệu quả của ISA trong điều trị IA

2.2. Phướng pháp nghiên cứu: Mô hình hóa kết hợp tổng quan tài liệu và tham vấn ý kiến chuyên gia.

Đề tài tiến hành xây dựng mô hình hóa phân tích CP-HQ dựa trên 2 bước như sau:

Bước 1: Xây dựng mô hình sơ bộ được thực hiện dựa trên phân tích tổng quan hệ thống theo hướng dẫn PRISMA

- Tìm kiếm các nghiên cứu: Đề tài tiến hành tìm kiếm trên các nguồn thư viện điện tử bao gồm: Pubmed, Cochrane, Embase để thu thập dữ liệu các nghiên cứu phân tích CP-HQ của ISA so với VORI trong điều trị IA với câu lệnh tìm kiếm dựa trên các từ khóa: "invasive aspergillosis", "cost-effectiveness" và toán tử AND.

- Sàng lọc và lựa chọn nghiên cứu: Các nghiên cứu tìm thấy được lựa chọn thông qua các tiêu chí lựa chọn (nghiên cứu trên người bệnh IA; nghiên 
cứu phân tích $\mathrm{CP}-\mathrm{HQ}$; can thiệp đánh giá là ISA; được viết bằng tiếng $A n h)$ và tiêu chí loại trừ (không phân tích CP-HQ của ISA so với ít nhất một thuốc cụ thể; chỉ số đầu ra không phải là ICER; không có bài toàn văn; tổng quan hệ thống, báo cáo ca hoặc hướng dẩn điều trị)

-Trích xuất, tổng hợp và trình bày dữ liệu các nghiên cứu: Các nghiên cứu đáp ứng tiêu chí lựa chọn và loại trừ được trích xuất thông tin các đặc điểm nghiển cứu (tên tác giả (quốc gia), năm nghiên cứu, đặc điểm dân số, can thiệp so sánh, đặc điểm mô hình, loại $\mathrm{CP}-\mathrm{HQ}$, số nhánh và các phân nhánh của mô hình).

-Xây dựng mô hình sơ bộ: Để có thể ghi nhận tất cả các thông số đầu vào, từ đó ước lượng thông số đầu ra và dự báo sự thay đổi của các thông số đầu ra dựa trên sự thay đổi của thông số đầu vào, mô hình xây dựng cần đảm bảo các đặc điểm trong cấu trúc thỏa mãn một số yêu cầu nhất định (Bảng 1).

Bảng 1. Những yêu cầu của mô hình sơ bộ

\begin{tabular}{|c|c|c|}
\hline TT & Đăcc điểm & Yêu câu \\
\hline 1 & Cấu trúc mô hình & $\begin{array}{c}\text { Bao gồm các trạng thái thể hiện diển tiến bệnh lý, các lựa chọn điều trị } \\
\text { và các tình huống có thể xảy ra cho mối lựa chọn điề trị }\end{array}$ \\
\hline 2 & Thông & $\begin{array}{l}\text { - Xác suất: tỉ lệ các kết quả có thể xảy ra ở mỗi lựa chọn điều trị } \\
\text { - Chi phí: đánh giá được chi phí của mỗi can thiệp sử dụng } \\
\text { - Hiệu quả: đánh giá được hiệu quả của mỗi can thiệp sử dung }\end{array}$ \\
\hline 3 & Thông s & Chỉ số gia tăng CP-HQ \\
\hline 4 & Ian điểm nghiên c & 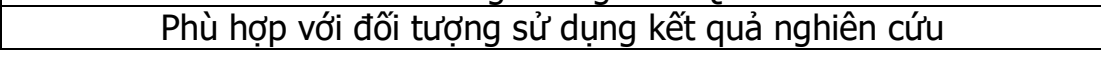 \\
\hline
\end{tabular}

Bước 2: Xây dựng mô hình hoàn chỉnh dựa trên tham vấn ý kiến chuyên gia

Để có cơ sở hiệu chỉnh mô hình sơ bộ, đề tài thực hiện tham vấn 10 chuyên gia lâm sàng những nội dung liên quan đến mô hình (đặc điểm và yêu cầu của mô hình). Các chuyên gia lâm sàng được chọn với tiêu chí sau đây:

-Tiêu chuẩn lứa chon: Chuyên gia làm việc tại một số bệnh viện chuyên khoa (Bênh viền Chợ Rẫy, bệnh viện Đại học Y Dược TPHCM, Viện Huyết học - Truyền máu Trung ương, Bệnh Viện Phổi Trung ương); chuyên khoa về hồi sức cấp cứu, hô hấp hoặc huyết học; từ 10 năm kinh nghiệm điều trị nhiễm nấm xâm lấn; đồng ý tham gia phỏng vấn.

-Tiêu chuẩn loại trứ: Không cung cấp đầy đủ các thông tin cho buổi phỏng vấn

Sau khi tham vấn ý kiến chuyên gia lâm sàng, mô hình sơ bộ sẽ được xây dựng trên phần mềm MS Excel 2016 với các trang tính toán, tham số đầu vào và đầu ra hoàn chỉnh.

\section{KẾT QUẢ NGHIÊN CứU}

\subsection{Xây dựng mô hình sơ bộ}

Tổng quan các mô hình phân tích CP-HQ của ISA trong điều trị IA. Đề tài tiến hành tìm kiếm bằng câu lệnh thồng qua 3 cơ sở dữ liệu điện tử, nghiên cứu truy xuất được 189 bài báo bao gồm 152 bài từ Pubmed, 26 bài từ Cochrane và 11 nghiên cứu từ Embase. Sau khi loại bỏ trùng lặp, tiến hành lựa chọn và loại trừ dựa theo các tiêu chí, đề tài thu được 4 nghiên cứu để đưa vào phân tích của các tác giả Harrington
$(M y \tilde{)})^{(4)}$, Floros (Anh) $)^{(3)}$, Floros (Thụy Điển) ${ }^{(2)}$ và Azanza (Tây Ban Nha) ${ }^{(1)}$.

Kết quả tổng hợp đặc điểm và cấu trúc mô hình của các nghiền cứu được trình bày trong bảng 2. Kết quả cho thấy, 4 nghiên cứu $\mathrm{CP}-\mathrm{HQ}$ đều thực hiện trên mô hình cây quyết định với điểm giống nhau là can thiệp so sánh, bao gồm hai nhánh điều trị là ISA và VORI. Tuy nhiên, mô hình của Harrington ${ }^{(4)}$ thể hiện các phân nhánh biếu thị kết quả cuối cùng là đáp ứng hoặc không đáp ứng lâm sàng và người bệnh sống sót hoặc tử vong sau khi điều trị. Đối với mô hình của 3 tác giả: Floros L. (Thụy Điển) (2), Floros L. (Anh) ${ }^{(3)}$ và Azanza (Tây Ban Nha) ${ }^{(1)}$, sau khi điều trị với ISA hoặc VORI mô hình tiếp tục phân nhánh. Dựa vào tình trạng đáp ứng lâm sàng của người bệnh mà người bệnh được tiếp tục với can thiệp bước 1 (nếu có đáp ứng) hoặc đổi sang can thiêpp bước 2 là AmB dạng liposom (L-AmB) (nếu không có đáp ứng) sau đó duy trì với VORI/posaconazole đường uống. Cuối cùng mô hình phân nhánh kết quả sống sót hoặc tử vong sau khi kết thúc điều trị ở mỗi nhánh.

Khoảng thời gian ghi nhận khác nhau ở 4 nghiên cứu, nghiên cứu của Harrington ${ }^{(4)}$ phân tích trong 1 lần nhập viện, 2 nghiên cứu của Floros $^{(2),}{ }^{(3)}$ và nghiên cứu của Azanza(1) phân tích và theo dõi trọn đời người bệnh. Cả 4 nghiên cứu đều đánh giá chi phí trực tiếp y tế, trong đó có 3 nghiên cứu (1), (2), (3) đánh giá hiệu quả dựa trên chỉ số QALYs, LYG và nghiên cứu của Harrington(4) đánh giá trên chỉ số lâm sàng. 
Bảng 2. Đặc điểm mô hình của các nghiên cứu

\begin{tabular}{|c|c|c|c|c|c|c|c|c|}
\hline STT & $\begin{array}{l}\text { Tác giả } \\
\text { (Năm) }\end{array}$ & $\begin{array}{l}\text { Loại mô } \\
\text { hình }\end{array}$ & $\begin{array}{c}\text { Đặc điểm } \\
\text { dân số }\end{array}$ & $\begin{array}{c}\text { Can } \\
\text { thiệp } \\
\text { só } \\
\text { sánh }\end{array}$ & $\begin{array}{l}\text { Số } \\
\text { lướng } \\
\text { nhánh }\end{array}$ & $\begin{array}{c}\text { Tên các phân } \\
\text { nhánh }\end{array}$ & $\begin{array}{c}\text { Khoảng } \\
\text { TG theo } \\
\text { dõi }\end{array}$ & $\begin{array}{c}\text { Loại chi } \\
\text { phí, } \\
\text { hiệu } \\
\text { quả }\end{array}$ \\
\hline 1 & \begin{tabular}{|c|} 
Harrington \\
R. và cS \\
$($ Mỹ) (2016) \\
$(4)$ \\
\end{tabular} & $\begin{array}{c}\text { Mô hình } \\
\text { cây quyết } \\
\text { định }\end{array}$ & $\begin{array}{l}\text { Người bệnh } \\
\text { IA }\end{array}$ & $\begin{array}{l}\text { ISA và } \\
\text { VORI }\end{array}$ & 10 & $\begin{array}{c}\text { ISA, VORI; đáp } \\
\text { ứng, không đáp } \\
\text { ứng; sống sót } \\
\text { hoặc tử vong } \\
\end{array}$ & 1 lần nhập & $\begin{array}{l}\text { Trực tiếp } \\
\text { Chỉ số } \\
\text { lâm sàng }\end{array}$ \\
\hline 2 & $\begin{array}{l}\text { Floros L. và } \\
\text { CS (TĐ) } \\
(2019)^{(2)}\end{array}$ & $\begin{array}{c}\text { Mô hình } \\
\text { cây quyết } \\
\text { định }\end{array}$ & $\begin{array}{l}\text { Người bệnh } \\
\text { IA }\end{array}$ & $\begin{array}{l}\text { ISA và } \\
\text { VORI }\end{array}$ & 14 & $\begin{array}{l}\text { ISA, VORI; } \\
\text { khống đổi } \\
\text { thuốc, đổi } \\
\text { thuốc; sống sót } \\
\text { hoặc tử vong }\end{array}$ & Trọn đời & $\begin{array}{c}\text { Trực tiếp } \\
\text { QALY, } \\
\text { LYG }\end{array}$ \\
\hline 3 & $\begin{array}{l}\text { Floros L. và } \\
\text { cS (Anh) } \\
(2020)^{(3)}\end{array}$ & $\begin{array}{c}\text { Mô hình } \\
\text { cây quyết } \\
\text { định }\end{array}$ & $\begin{array}{c}\text { Người bệnh } \\
\text { nhiếm nấm } \\
\text { xâm lấn trước } \\
\text { khi chẩn đoán } \\
\text { phân biệt } \\
\text { mầm bệnh }\end{array}$ & $\begin{array}{l}\text { ISA và } \\
\text { VORI }\end{array}$ & 14 & $\begin{array}{l}\text { ISA, VORI; } \\
\text { khống đổi } \\
\text { thuốc, đổi } \\
\text { thuốc; sống sót } \\
\text { hoặc tử vong }\end{array}$ & Trọn đời & $\begin{array}{c}\text { Trực tiếp } \\
\text { QALY, } \\
\text { LYG }\end{array}$ \\
\hline 4 & $\begin{array}{l}\text { Azanza J. và } \\
\text { cS (TBN) } \\
(2020)(1)\end{array}$ & $\begin{array}{c}\text { Mô hình } \\
\text { cây quyết } \\
\text { định }\end{array}$ & $\begin{array}{l}\text { Người bệnh } \\
\text { IA }\end{array}$ & $\begin{array}{l}\text { ISA và } \\
\text { VORI }\end{array}$ & 14 & $\begin{array}{c}\text { ISA, VORI; } \\
\text { khống đổi } \\
\text { thuốc, đổi } \\
\text { thuốc; sống sót } \\
\text { hoặc tứ vong }\end{array}$ & Trọn đời & $\begin{array}{c}\text { Trực tiếp } \\
\text { QALY, } \\
\text { LYG }\end{array}$ \\
\hline
\end{tabular}

Ghi chú: TĐ: Thụy Điển; TBN: Tây Ban Nha

Mô hình sơ bô phân tích CP-HQ. Dưa trên tổng quan các mô hình và các yêu cầu xây dựng mô hình sơ bộ phân tích CP-HQ trong điều trị IA với cấu trúc được trình bày trong hình 1.

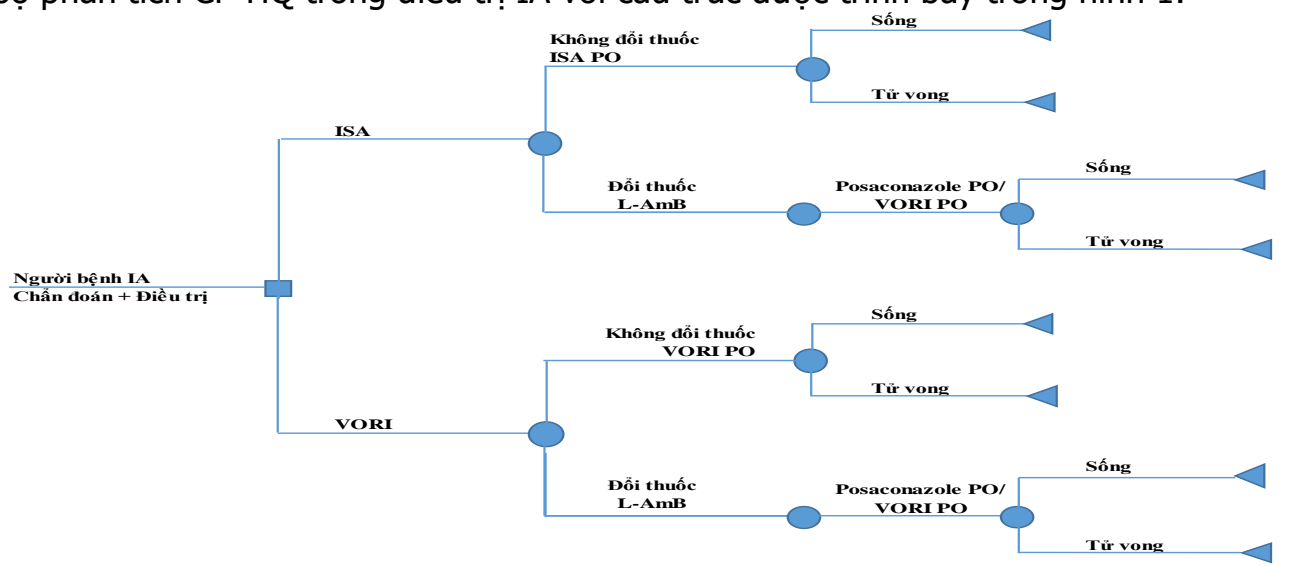

Hình 1. Cấu trúc mô hinh phân tích $C P-H Q$

Theo hình 1 , mô hình được xây dựng bằng $\mathrm{HQ}$ ) dựa trên quan điểm cơ quan chi trả BHYT phần mềm Microsoft Excel với cấu trúc mô phỏng 2 phương án điều trị IA bao gồm ISA và VORI. Mô hình bao gồm các trang tính toán các tham số đầu vào của mô hình (chi phí điều trị, xác suất mỗi nhánh, hiệu quả điều trị) từ đó tính toán được tham số đầu ra (chỉ số gia tăng CP-

\section{Việt Nam.}

\subsection{Xây dựng mô hình hoàn thiện}

Tham vấn ý kiến chuyên gia. Dưa trên tham vấn ý kiến nhóm chuyên gia lâm sàng, đề tài ghi nhận những hiệu chỉnh cần được thực hiện với kết quả trình bày trong bảng 3 .

\section{Bảng 3. Nôi dung cân hiêu chỉnh của mô hình sơ bô}

\section{Nội dung \\ Đặc điểm mô hình \\ Ý kiến của các chuyên gia}

Số nhánh điều trị ở Mô hình bao gồm 2 nhánh: bước 1 ISA và VORI.

Bổ sung nhánh AmB 


\begin{tabular}{|c|c|c|}
\hline \begin{tabular}{|l|} 
Phân nhánh điều \\
trị bước 2 (đáp \\
ứng với bước 1 ) \\
\end{tabular} & $\begin{array}{l}\text { - ISA: Sử dụng tiếp ISA PO } \\
\text {-VORI: Sử dụng tiếp VORI PO }\end{array}$ & $\begin{array}{l}\text {-AmB: Sử dụng tiếp AmB PO. Sau đó duy trì } \\
\text { bằng PO với } 1 \text { trong các thuốc: itraconazole, } \\
\text { VORI }\end{array}$ \\
\hline $\begin{array}{l}\text { Phân nhánh điêu } \\
\text { trị bước } 2 \text { (không } \\
\text { đáp ứng với bước } \\
1 \text { ) }\end{array}$ & $\begin{array}{c}\text {-ISA: chuyển sang L-AmB. Sau đó } \\
\text { duy trì với PO posaconazole hoặc } \\
\text { VORI } \\
\text {-VORI: tương tự ISA }\end{array}$ & $\begin{array}{l}\text {-ISA: đối thuốc AmB/Amphotericin B phức } \\
\text { hợp lipid (ABLC). Sau đó duy trì PO với } 1 \\
\text { trong } 2 \text { thuốc: itraconazole, VORI. } \\
\text {-VORI: tương tự với ISA } \\
\text {-AmB: đổi thuốc VORI IV hoăc PO } \\
\text { itraconazole/ABLC IV. Sau đó nhánh ABLC } \\
\text { duy trì PO với } 1 \text { trong } 2 \text { thuốc: VORI, } \\
\text { itraconazole. }\end{array}$ \\
\hline $\begin{array}{l}\text { Phân nhánh cuối } \\
\text { cùng }\end{array}$ & Sống sót hoặc tử vong & Không thay đổi \\
\hline \multicolumn{3}{|c|}{ 2. Chức năng của mô hình } \\
\hline $\begin{array}{l}\text { Mô hình thể hiện } \\
\text { được } 1 \text { số chức } \\
\text { năng trong điêuu trị } \\
\text { IA }\end{array}$ & $\begin{array}{l}\text { - Mô hình phản ánh được đây đủ đă̆c } \\
\text { điểm của điều trị nhiếm nấm xâm lẩn } \\
\text { - Cho phép phân tích cấu trúc chi phí } \\
\text { điêuu trị theo từng phác đồ điêu trị } \\
\text { - Mô hình cho phép cập nhất các } \\
\text { thông số đâu vào để có cái nhìn } \\
\text { tổng quan về chi phí điều trị IA ở } \\
\text { Việt Nam }\end{array}$ & $\begin{array}{l}\text { Bổ sung chức năng sau: } \\
\text { Cho phép đánh giá và lựa chọn được thuốc } \\
\text { điều trị thích hợp cho IA, đảm bảo tính hiệu } \\
\text { quả và kinh tế nhất. }\end{array}$ \\
\hline
\end{tabular}

Mô hình phân tích CP-HQ hoàn chỉnh

Cấu trúc của mô hình. Mô hình cây quyết định mô tả các phương án điều trị của bệnh IA được diễn tả trong hình 2.

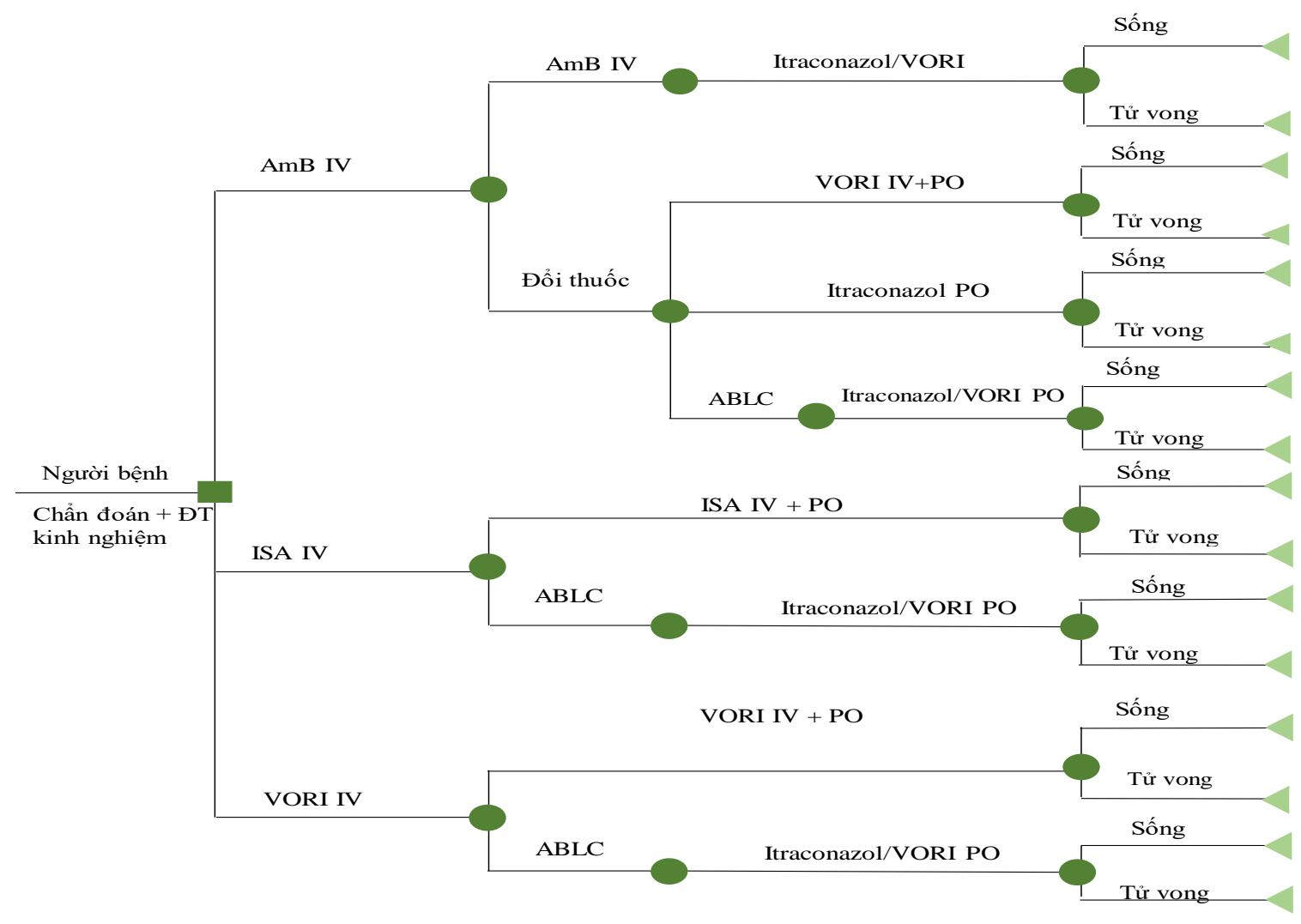

Hình 2. Cấu trúc mô hình cây quyêt định hoàn chỉnh 
Theo hình 2, sau khi tham vấn ý kiến chuyên gia lâm sàng, mô hình hoàn chỉnh được xây dựng bằng phần mềm Microsoft Excel 2016 mô phỏng 3 liệu pháp điêu trị IA là ISA, VORI và AmB.

Giả định của mô hình: Xác suất giữa các lựa chọn điều trị ổn định và không thay đổi trong suốt quá trình điều trị; người bệnh tuân thủ điều trị.

\section{Chức năng của mô hình}

- Cho phép ước lượng chi phí và hiệu quả trong điều trị IA mỗi năm theo từng phác đồ điều trị.

- Cho phép phân tích cấu trúc chi phí điều trị trong điều trị IA mỗi năm theo từng phác đồ điều tri.

- Cho phép cập nhật các thông số đầu vào để có cái nhìn tổng quan về chi phí điêu trị IA ở Việt Nam.

- Cho phép đánh giá và lựa chọn được thuốc điều trị thích hợp cho IA, đảm bảo tính hiệu quả và kinh tế nhất.

Thông số của của mô hình

Bảng 4. Thông số đầu vào và đầu ra của mô hình cây quyêt định

\begin{tabular}{|c|c|c|c|}
\hline STT & Các thông số & Nội dung & Tên gọi trang tính toán \\
\hline \multicolumn{4}{|c|}{ Thông số đầu vào } \\
\hline 1 & Xác suất & $\begin{array}{c}\text { Tần suất lựa chọn điều trị ở các phương } \\
\text { án điêu tri IA }\end{array}$ & Xác suất \\
\hline 2 & Chi phí điều trị & $\begin{array}{l}\text { Bao gồm chi phí điều trị ở bước đầu và } \\
\text { chi phí điều trị ở các phân nhánh }\end{array}$ & $\begin{array}{l}\text { CP thuốc, CP dịch vụ y tế, } \\
\text { CP điều trị biến cố bất lợi }\end{array}$ \\
\hline 3 & Hiệu quả & $\begin{array}{l}\text { Kết quả sau khi kết thúc điều trị, bao } \\
\text { gôm: tỉ lệ sống còn và tỉ lệ tử vong }\end{array}$ & Xác suất tử vong \\
\hline \multicolumn{4}{|c|}{ Thông số đâu ra } \\
\hline 1 & $\begin{array}{l}\text { Chỉ số gia tăng } \\
\text { CP-HQ (ICER) }\end{array}$ & $\begin{array}{c}\text { Cho biết chi phí phải trả thêm cho một } \\
\text { đơn vị hiệu quă tăng thêm }\end{array}$ & Kết quả \\
\hline 2 & Phân tích độ nhạy & $\begin{array}{c}\text { Mức độ ảnh hưởng của các yếu tố đến } \\
\text { mô hình CP-HQ }\end{array}$ & Phân tích độ nhạy \\
\hline
\end{tabular}

\section{BÀN LUẬN}

Đề tài đã xây dựng hoàn thiện mô hình phân tích CP-HQ của ISA trong điều trị IA trên nền tảng Microsoft Excel 2016. Đây được xem là công cụ quan trọng để đánh giá tính CP-HQ của các can thiệp trong điều trị IA cũng như ước lượng mức độ ảnh hưởng của các thông số đầu vào lên kết quả và tính chắc chắn của các kết quả thu được. Mặc dù nhiêu nghiên cứu phân tích $\mathrm{CP}-\mathrm{HQ}$ của ISA đã được tiến hành bằng phương pháp mô hình hóa. Tuy nhiên đến thời điểm hiện tại, tại Việt Nam vẫn chưa có đề tài nào tương tự được thực hiện. Hơn thế nữa, để có thể ứng dụng mô hình tại Việt Nam, cần có những điều chỉnh phù hợp với thực tế lâm sàng. Vì vậy, là nghiên cứu đầu tiên được thực hiện liên quan đến chủ đề này, đề tài mang tính ứng dụng cho những nghiên cứu về $\mathrm{CP}-\mathrm{HQ}$ của các can thiệp trong điều trị IA trong tương lai đồng thời có giá trị tham khảo cho những đề tài tương tự.

Mô hình cây quyết định được lựa chọn phù hợp với đặc điểm cấp tính của bệnh lý nhiễm nẩm xâm lấn. Mô hình sơ bộ của nghiên cứu tương đương với $3 / 4$ nghiên cứu phân tích $\mathrm{CP}$ HQ của ISA đã được công bố(1), (2), (3). Đây là mô hình mô phỏng được đầy đủ quá trình điều trị IA, các phác đồ điêu trị tấn công và điều trị thay thế phù hợp với Hướng dẫn chẩn đoán và điều trị IA của ESCMID-ECMM-ERS năm 2017, thể hiện các triệu chứng ban đầu đến kết quả cuối cùng của người bệnh (tử vong hoặc giải quyết được tình trạng nhiễm trùng) trong điều trị IA với các thuốc kháng nấm. Sau khi tham vấn các chuyên gia lâm sàng, mô hình bổ sung thêm nhánh điêu trị với $A m B$ và các liệu pháp duy trì điều trị bằng đường uống với một trong hai thuốc: itraconazole, VORI và phân nhánh cuối cùng mô hình biểu thị kết quả điều trị phù hợp với thực tế lâm sàng tại Việt Nam.

Bệnh lý nhiễm nẩm Aspergillus xâm lấn là một trong những bệnh lý nhiểm trùng mới nổi cần được quan tâm và có tỷ lệ tử vong cao và ISA là một thuốc mới. Mô hình phân tích $\mathrm{CP}-\mathrm{HQ}$ có thể cung cấp cái nhìn toàn diện về tính $\mathrm{CP}-\mathrm{HQ}$ của các liệu pháp can thiệp trong điêu trị IA, cung cấp công cụ hữu ích cho bác sĩ và cơ quan quản lý y tế lựa chọn phác đồ điều trị phù hợp, cũng như hoạch định chi phí điều trị nhằm tối ưu hóa các liệu pháp điều trị.

\section{KẾT LUÂ̂N}

Mô hình được xây dựng bằng phần mềm Microsoft Excel 2016 với cấu trúc mô phỏng quá trình diễn tiến bênh lý IA cho phép phân tích CP$\mathrm{HQ}$ của ISA, VORI và $A m B$ trong điều trị IA và dự báo tính không chắc chắn của kết quả. Mô hình có thể tham khảo để đánh giá $\mathrm{CP}-\mathrm{HQ}$ của các can thiệp khác trên cùng bệnh lý với sự điều chỉnh các thông số đầu vào phù hợp. 


\section{TÀI LIÊU THAM KHẢO}

1. Azanza J. R. et al. (2021), "The costeffectiveness of isavuconazole compared to voriconazole, the standard of care in the treatment of patients with invasive mould diseases, prior to differential pathogen diagnosis in Spain", Mycoses. 64, pp. 66-67.

2. Floros L. et al. (2019), "Cost-effectiveness analysis of isavuconazole versus voriconazole for the treatment of patients with possible invasive aspergillosis in Sweden", BMC Infectious Dieases. 19 (134), pp. 1-11.

3. Floros L. et al. (2020), "The cost-effectiveness of isavuconazole compared to the standard of care in the treatment of patients with invasive fungal infection prior to differential pathogen diagnosis in the United Kingdom", Journal of Medical Economics. 23, pp. 86-97.

4. Harrington R. et al. (2016), "Cost-Effectiveness Analysis of Isavuconazole vs. Voriconazole as First-Line Treatment for Invasive Aspergillosis", Adv Ther. 34, pp. 207-220.

5. Schmiedel Y. et al. (2016), "Common invasive fungal diseases: an overview of invasive candidiasis, aspergillosis, cryptococcosis, and Pneumocystis pneumonia", Swiss Medical Weekly, pp. 1-12.

\section{TỔNG QUAN HÊ THỐNG VÀ PHÂN TÍCH GộP CHI PHÍ - HIỂU QUẢ CỦA OMALIZUMAB TRONG ĐÎ̂̀U TRI HEN PHẾ QUẢN}

\section{TÓM TẮT}

Phân tích chi phí - hiệu quả các can thiệp trong điều trị hen phế quản (HPQ) được thực hiện ở nhiều quốc gia trên thế giới, trong đó có omalizumab. Tổng quan hệ thống và phân tích gộp chi phí - hiệu quả của omalizumab trong điều trị $\mathrm{HPQ}$ được thực hiện theo hướng dẫn PRISMA dựa trên nguồn dữ liệu Pubmed, Cochrane và Embase với các tiêu chí lựa chọn và loại trừ phù hợp và đánh giá chất lượng NC theo bảng kiểm CHEERS. Tổng quan hệ thống và phân tích gộp được thực hiện thông qua chỉ số ICER/QALY quy đổi thống nhất sang Đôla Mỹ (USD) năm 2020 dựa vào chỉ số giá tiêu dùng (CPI). Với 212 NC được tìm thây, sau khi sàng lọc với tiêu chí lựa chọn và loại trừ, 15 NC được đưa vào tổng quan và 06 NC được đưa vào phân tích gộp. Điểm chất lượng NC dao động từ 17 đến 22 điểm theo bảng kiểm CHEERS với $60 \%$ NC đat chất lượng tốt. Đề tài ghi nhận sự chênh lệch khá lớn về chỉ số ICER/QALY giữa các NC, dao động từ \$11.769/QALY đễn \$897.559/QALY. Với bệnh nhân hen dị ứng dai dẳng nặng không kiểm soát, kể cả với corticosteroids, liệu pháp bổ sung omalizumab có thể đạt chi phí - hiệu quả so với liệu pháp chuẩn. Kết quả phân tích gộp cho thấy so với liệu pháp chuẩn, chỉ số ICER/QALY của omalizumab đạt giá trị \$59.052/QALY (khoảng tin cậy 95\%: \$34.457 - \$83.648/QALY; $\mathrm{p}<$ $0,01)$. Liệu pháp bổ sung omalizumab có thể xem là đạt chi phí - hiệu quả khi so sánh với liệu pháp chuẩn trong trường hợp HPQ nghiêm trọng.

Từ khóa: chi phí - hiệu quả, hen phễ quản, omalizumab, tổng quan hệ thống.

*Đại Học Y Dược Thành Phố Hồ Chí Minh Chịu trách nhiệm chính: Nguyễn Thị Thu Thủy Email: nguyenthuthuy@ump.edu.vn Ngày nhận bài: 25.8.2021

Ngày phản biện khoa học: 22.10.2021

Ngày duyệt bài: 29.10.2021
Lữ Thị Bích Huyền*, Nguyễn Thị Thu Thủy*

\section{SUMMARY}

SYSTEMATIC REVIEW AND META - ANALYSIS OF THE COST - EFFECTIVENESS OF OMALIZUMAB IN THE TREATMENT FOR ASTHMA

Cost-effectiveness analyses of interventions in the treatment for asthma have been performed in many countries around the world, including omalizumab. Systematic review and meta - analysis of the current state of the literature on the cost-effectiveness of omalizumab in the treatment for asthma has been conducted according to PRISMA guidelines based on database sources Pubmed, Cochrane and Embase with appropriate selection and exclusion criteria and assess quality of studies according to CHEERS. The systematic review and meta-analysis were performed through the ICER/QALY index converted to US Dollars (USD) 2020 based on the consumer price index (CPI). With 212 studies found based on search keywords, after screening according to selection and exclusion criteria, 06 studies were included in the meta analysis. According to the CHEERS checklist, the quality of the studies ranging from 17 to 22 points with $60 \%$ good quality studies. This systematic review noted a relatively large variation in ICER/QALY between studies, ranging from $\$ 11,769 / \mathrm{QALY}$ to $\$ 897,559 / \mathrm{QALY}$. In patients with uncontrolled severe persistent allergic asthma, particularly with corticosteroids, add-on therapy with omalizumab may be considered cost-effective when compared with standard therapy. The results of meta - analysis showed that ICER/QALY of add-on therapy with omalizumab compared with standard therapy resulted in \$59.052/QALY (95\% confidence interval: $\$ 34,457$ $\$ 83,648 / \mathrm{QALY} ; \mathrm{p}<0.01)$. The add-on therapy with omalizumab may be considered cost-effective when compared with standard therapy in severe asthma.

Keywords: Cost-effectiveness, asthma, omalizumab, systematic review.

\section{I. ĐẶT VẤN ĐỀ}

Theo Tổ chức $Y$ tế Thế giới (World Health 